\title{
Pengaruh Guided Discovery Learning Terhadap Kemampuan Pemecahan Masalah Turunan Dan Integral Mahasiswa Pendidikan Teknik Bangunan Universitas Palangka Raya Tahun 2020/2021
}

\author{
Revianti Coenraad \\ Program Studi Pendidikan Teknik Bangunan, Jurusan Pendidikan Teknologi dan \\ Kejuruan, FKIP, Universitas Palangka Raya, Indonesia \\ Email: revianti@ptb.upr.ac.id
}

Diterima: 26-09-2021; Diperbaiki:01-10-2021; Disetujui:10-10-2021

\begin{abstract}
ABSTRAK
Mata kuliah di Perguruan Tinggi terkhusus pada Prodi Pendidikan Teknik Bangunan FKIP UPR peran matematika sangat penting. Sebagian mahasiswa memandang pembelajaran matematika adalah pembelajaran yang sulit dan membosankan. Selama ini model yang digunakan juga masih sering berpusat pada dosen (teacher-centered), dimana kegiatan belajar mengajar didominasi oleh dosen dan mahasiswa hanya mendengar, mencatat, mengerjakan soal latihan yang diberikan. Mengamati hal tersebut perlu diupayakan suatu bentuk pembelajaran yang mampu meningkatkan keaktifan dan hasil belajar yakni dengan salah satu model pembelajaran Guided Discovery Learning. Model ini dapat memberikan penekanan kondisi belajar dengan secara aktif dan dapat menemukan/menyelidiki sendiri rumus-rumus berdasarkan materi yang sedang dipelajari dengan bantuan dari dosen dan dapat melatih mahasiswa dalam mengingat materi yang sudah dipelajari. Jenis penelitian ini adalah penelitian deskriptif. Data kuantitatif berupa skor yang diperoleh dari tes hasil belajar mahasiswa Pendidikan Teknik Bangunan Semester Genap 2020/2021 yang memprogramkan Mata Kuliah Matematika Teknik. Penelitian ini dilaksanakan pada bulan September 2020 sampai Januari 2021 di Pendidikan Teknik Bangunan FKIP Universitas Palangka Raya. Terdapat pengaruh yang signifikan dibuktikan dengan analisi uji t-test dengan hasil $t_{\text {hitung }}>t_{\text {tabel }}$ dengan nilai thitung $=\mathbf{2 2 , 1}$ sedangkan untuk ttabel $=\mathbf{2 , 0 4}$ dengan kepercayaan $\mathbf{0 , 0 5 \%}$, maka dapat perbedaan yang signifikan pada pembelajaran yang menggunakan model pembelajaran guided discovery learning.
\end{abstract}

Kata Kunci: hasil belajar, model pembelajaran, teacher-centered, guided discovery learning

\section{PENDAHULUAN}

Dalam mata kuliah di Perguruan Tinggi terkhusus pada Prodi Pendidikan Teknik Bangunan FKIP UPR peran matematika sangat penting, masih banyak mahasiswa yang sukar mempelajari matematika, hal ini berdasarkan nilai pada akhir semester yang masih rendah pada batas kelulusan kurang dari C (60). Sebagian mahasiswa memandang pembelajaran matematika adalah pembelajaran yang sulit dan membosankan. Hal ini sesuai dengan yang dikemukakan oleh Hudoyo bahwa "Di dalam proses belajar matematika umumnya siswa kurang menyenangi bidang matematika, hal ini disebabkan oleh kecenderungan bahwa yang ditampilkan atau yang diajarkan kepada siswa adalah sederet rumus-rumus yang bersifat abstrak dan membosankan". Oleh sebab itu dalam pembelajaran matematika perlu diperhatikan perencanaan pembelajaran yang tepat agar dapat menentukan tingkat keberhasilan belajar mengajar. Salah satu hal yang 
diperhatikan dalam perencanaan pembelajaran matematika adalah pemilihan model yang sesuai. Mengamati hal tersebut perlu diupayakan suatu bentuk pembelajaran yang mampu meningkatkan keaktifan dan hasil belajar siswa adalah dengan salah satu model pembelajaran Guided Discovery Learning. Penerapan model GDL dapat memberikan penekanan kondisi belajar dengan suasana aman dan nyaman sehingga siswa dapat belajar secara aktif, siswa dapat menemukan/menyelidiki sendiri rumus-rumus berdasarkan materi yang sedang dipelajari dengan bantuan dari guru dan dapat melatih siswa dalam mengingat materi yang sudah dipelajari sehingga pembelajaran berjalan dengan efektif dan optimal. Dengan kondisi ini diharapkan akan mendorong mahasiswa untuk melakukan proses berfikir logis, kreatif serta proses dalam menyelesaikan masalah akan lebih baik. Konsep-konsep matematika tidak hanya pada kemampuan dalam menghitung akan tetapi membantu dalam kemajuan ilmu pengetahuan dan teknologi. Model pembelajaran Guided Discovery Learning menurut Eggen (2017) adalah suatu model pembelajaran dimana siswa dihadapkan pada situasi yang bebas dalam mengapresiasikan dirinya untuk menyelidiki rumus yang digunakan, di mana guru memberi siswa contoh-contoh topik spesifik dan memandu siswa untuk memahami topik tersebut. Salah satu keunggulan model Guided Discovery Learning adalah peserta didik dapat berkembang untuk menemukan sendiri pengetahuannya sesuai dengan kemampuannya sehingga peserta didik aktif dan tidak hanya mendengar penjelasan dari guru. Berdasarkan latar belakang masalah yang diuraikan di atas, penulis bermaksud untuk mengadakan penelitian tentang "Pengaruh Guided Discovery Learning terhadap Kemampuan Pemecahan Masalah Mata Kuliah Matematika Teknik dengan Materi Pembelajaran Turunan dan Integral Mahasiswa Pendidikan Teknik Bangunan FKIP UPR Semester Genap 2020/2021”.

Hasil belajar adalah kemampuan yang diperoleh anak setelah melalui kegiatan belajar. Dalam hal ini hasil belajar diartikan sebagai salah satu hal yang dijadikan pusat perhatian dalam dunia pendidikan karena hasil belajar menentukan tingkat keberhasilan dari proses belajar mengajar.

Pembelajaran Konvensional adalah suatu pengajaran yang mana dalam proses belajar masih menggunakan cara lama. Guru memegang peranan penting dalam menentukan urutan langkah dalam menyampaikan materi kepada siswa. Sedangkan peranan siswa adalah mendengarkan secara teliti dan mencatat pokok-pokok yang penting yang dikemukakan oleh guru.

Model pembelajaran Guided Discovery Learning dikembangkan oleh Jerome Seymour Bruner. Menurut Zuhdan Kun Praetyo dalam Jamil (2013) mengatakan bahwa penemuan (discovery learning) dibedakan menjadi dua, yaitu penemuan bebas (free discovery) dan penemuan terpadu/terbimbing (guided discovery). Model pembelajaran GDL atau penemuan terbimbing merupakan model pembelajaran yang menciptakan situasi belajar yang melibatkan siswa belajar secara aktif dan mandiri dalam menemukan/menyelidiki suatu konsep, pemahaman, dan menyelesaikan masalah. Proses penemuan tersebut membutuhkan guru sebagai 
fasilitator. Ciri khas model pembelajaran Guided Discovery Learning adalah dengan model pembelajaran ini siswa dapat menemukan/ menyelidiki suatu konsep dengan bimbingan atau arahan yang diberikan oleh guru sehingga siswa akan lebih mudah dalam menyelesaikan soal-soal yang berhubungan dengan konsep tersebut, karena dengan siswa yang menemukan/menyelidiki sendiri suatu konsep akan lebih mudah di pahami, dimengerti dan mudah di ingat. Sebagaimana yang diketahui bahwa semua model pembelajaran mempunyai kelebihan/keuntungan dan kekurangan, demikian pula dengan model pembelajaran Guided Discovery Learning. Kelebihan model pembelajaran Guided Discovery Learning yaitu:

1. Siswa akan lebih aktif dalam kegiatan belajar karena siswa dapat berpikir dan menggunakan kemampuannya untuk menemukan hasil akhir.

2. Siswa memahami benar bahan pembelajaran karena siswa mengalami sendiri proses menemukannya. Sesuatu yang diperoleh dengan cara ini akan lebih lama diingat.

3. Menemukan sendiri menimbulkan rasa puas. Kepuasan batin mendorong siswa ingin melakukan penemuan lagi hingga minat belajarnya meningkat.

4. Model ini dapat melatih siswa untuk lebih banyak belajar sendiri.

5. Dapat menanamkan rasa ingin tahu.

6. Menimbulkan kerja sama dan interaksi antar siswa.

Berikut beberapa kekurangan model pembelajaran Guided Discovery Learning antara lain:

1. Model pembelajaran Guided Discovery Learning banyak menyita waktu.

2. Tidak semua siswa mampu melakukan penemuan, apabila bimbingan guru tidak sesuai dengan kesiapan pengetahuan siswa.

3. Model pembelajaran Guided Discovery Learning dalam pembelajaran matematika hanya cocok untuk pokok bahasan tertentu.

Berdasarkan penjelasan tersebut, peneliti menyimpulkan bahwa model pembelajaran Guided Discovery Learning tidak hanya memiliki banyak kelebihan, tetapi juga beberapa kelemahan. Oleh karena itu perlu adanyapemahaman yang mendalam mengenai model inisupaya dalam penerapannya dapat terlaksana dengan efektif.

\section{Tahapan Model Pembelajaran Guided Discovery Learning}

Agar pelaksanaan proses pembelajaran dengan menggunakan model pembelajaran Guided Discovery Learning berjalan dengan efektif, ada beberapa langkah yang perlu ditempuh oleh guru yaitu sebagai berikut:

1. Menjelaskan tujuan/mempersiapkan siswa. Yakni guru menyampaikan tujuan pembelajaran, melakukan apersepsi dengan tanya jawab sederhana mengenai materi sehingga siswa dapat terlibat dalam kegiatan pembelajaran.

2. Orientasi masalah. Guru memberikan motivasi kepada siswa dan mendengar penjelasan tentang masalah sederhana yang berkenaan dengan materi pembelajaran. 
3. Merumuskan hipotesis. Membimbing siswa merumuskan hipotesis sesuai dengan permasalahan yang dikemukakan.

4. Melakukan kegiatan penemuan. Siswa melakukan kegiatan penemuan dengan bimbingan guru dan siswa diarahkan untuk memperoleh informasi yang diperlukan.

5. Mepresentasikan hasil kegiatan penemuan. Yakni guru membimbing siswa dalam menyajikan hasil kegiatan, merumuskan kesimpulan/menemukan suatu konsep.

6. Mengevaluasi kegiatan penemuan. Yakni siswa mengevaluasi langkah-langkah kegiatan yang telah dilakukan.

\section{METODOLOGI PENELITIAN}

Pendekatan dan jenis yang digunakan dalam penelitian ini menggunakan pendekatan penelitian kuantitatif. Di mana penelitian kuantitatif berupa angkaangka, dengan jenis penelitian One-Group Pretest-Posttest Design dalam bentuk tes awal-tes akhir kelompok tunggal. (Sugiyono,2010:110)

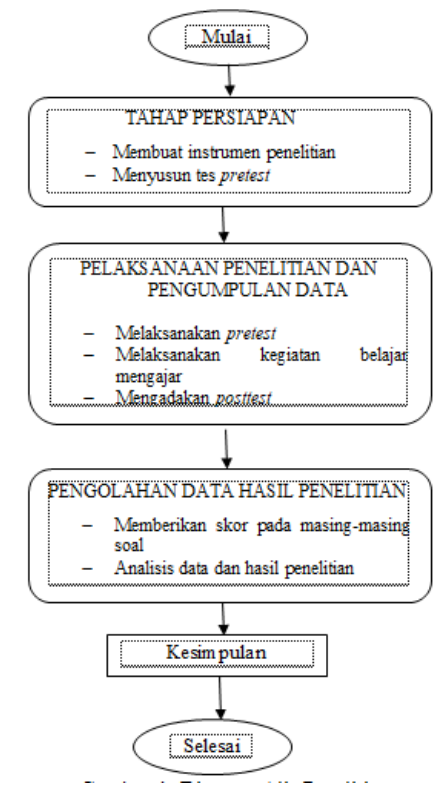

Gambar 1. Diagram Alir Penelitian

Penelitian hanya menggunakan satu kelas experimen tanpa dengan menggunakan kelompok kontrol dimana yang akan diuji nantinya hanya pre-test dan post-testnya saja. Pre-test diberikan untuk mengetahui kemampuan mahasiswa sebelum dimulainya treatment atau perlakuan, sedangkan untuk yang post-test nya untuk mengetahui kemampuan setelah diberikannya treatment. Maka dalam desain yang akan ditentukan hanya mempuyai dua kali observasi yaitu sebelum experimen $\left(\mathrm{O}_{1}\right)$ disebut dengan pre-test dan observasi sesudah experiment $\left(\mathrm{O}_{2}\right)$ post-test. Maka 
dapat diasumsikan bahwa hasil belajar peserta didik $=\left(\mathrm{O}_{2}-\mathrm{O}_{1}\right)$. (Chandra Gaol, 2015)

Instrumen penelitian adalah alat atau fasilitas yang digunakan peneliti untuk mengumpulkan data agar dalam pekerjaan lebih mudah dan dapat hasil yang akurat dan lebih baik, lengkap dan sistematis sehingga mudah untuk diolah (Arikunto,2002:134).

Instrumen penelitian yang dipergunakan dalam peneliti ini adalah berupa:

a. Pre test atau test tertulis kepada mahasiswa dengan bentuk essay yang disusun sesuai dengan materi yang diajarkan. Instrument ini digunakan untuk mengetahui kemampuan awal siswa dalam ketercapaian proses pembelajaran sebelum dan setelah menggunakan model pembelajaran guided discovery learning

b. Post test yang bertujuan untuk mengetahui apakah semua materi yang sudah diajarkan dapat dikuasai sebaik-baikya oleh mahasiswa. Materi test yang akan diberikan pada saat post test sama dengan pre test awal.

Validitas dilakukan untuk mengetahui ketepatan dan kelayakan instrumen sebagai alat ukur terhadap konsep atau variabel yang akan diukur, sehingga apa yang seharusnya diukur benar-benar dapat terukur (C Kosmawanti, 2017)

Untuk pengujian validitas test si peneliti melakukan uji validitas berdasarkan pendapat para ahli (jugment experts) Sugiyono (2010: 177). Dimana para ahli nanti diminta untuk memberikan keputusan untuk intrument yang akan dilakukan dengan perbaikan atau tidak. Jumlah tenaga ahli (ratter) yang digunakan untuk menguji instrumen soal sebanyak tiga orang pada umumya dengan gelar master sesuai dengan bidang dan lingkup yang akan diteliti. Dosen menguji instrumen dengan para ahli di mana kelas yang akan diteliti hanya satu kelas. Di sini dosen nanti akan menayakan uji instrumen terhadap satu dosen lain yang bersangkutan yang dalam bidang dan ruang lingkup dalam materi turunan dan integral pada Mata Kuliah Matematika Teknik . Butir instrumen dikatakan valid jika hasil telaah dari tiga ratter/ahli paling sedikit dua orang menyatakan bahwa butir soal atau pertayaan tersebut dapat atau layak digunakan.

Sebelum dikonsultasikan dengan ratter tiap-tiap butir instrumen haruslah mengacu pada kriteria-kriteria yang telah dibatasi,yaitu:

1. Rumusan butir instrumen telah sesuai/mengacu dengan indikator atau kisi-kisi instrumen.

2. Bahasa yang digunakan pada tiap butir pertayaan jelas dan dapt dipahami.

3. Rumusan butir instrumen tidak menimbulkan penafsiran ganda yang dapat menyulitkan responden untuk memberikan jawaban.

Menurut Arikunto (2010:208), untuk menghitung validitas instrumen berupa test, menggunakan Indeks Kesukaran (P) dan Daya pembeda (D). Rumus Indeks kesukaran sebagai berikut :

$$
\mathrm{P}=\frac{B}{J S}
$$




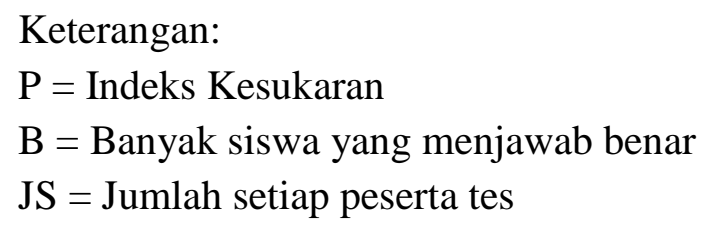

Dengan kriteria Indeks kesukaran $(\mathrm{P})$.

$$
\begin{aligned}
& 0,00 \leq \mathrm{P}<0,30 \text { soal sukar } \\
& 0,30 \leq \mathrm{P}<0,70 \text { soal sedang } \\
& 0,70 \leq \mathrm{P}<1,00 \text { soal mudah }
\end{aligned}
$$

Sedangkan untuk mengetahui daya pembeda tiap butir soal, menggunakan rumus sebagai berikut :

$$
\mathrm{D}=\frac{B A}{J A}-\frac{B B}{J B}
$$

Keterangan :

$\mathrm{D}$ = Daya pembeda soal

$\mathrm{BA}=$ Banyak siswa kelompok atas yang menjawab benar

$\mathrm{BB}=$ Banyak siswa kelompok bawah yang menjawab benar

$\mathrm{JA}=$ Banyak siswa kelompok atas (27\% dari jumlah seluruh siswa)

$\mathrm{JB}=$ Banyak siswa kelompok bawah (27\% dari jumlah seluruh siswa)

Dengan kriteria daya pembeda (D) sebagai berikut :

$$
\begin{aligned}
& \mathrm{D}<0,00 \text { sangat jelek } \\
& 0,00 \leq \mathrm{D}<0,20 \text { Jelek } \\
& 0,20 \leq \mathrm{D}<0,40 \text { Cukup } \\
& 0,40 \leq \mathrm{D}<0,70 \text { Baik } \\
& 0,70 \leq \mathrm{D}<1,00 \text { Baik sekali }
\end{aligned}
$$

Pada validitas soal test, soal yang diyatakan valid jika memiliki Indeks Kesukaran yaitu $0,25 \geq \mathrm{P}<0,75$ dan untuk Daya pembeda $\mathrm{D} \geq 0,25$. Maka jika salah satu soal kriteria tidak memenuhi,maka soal dinyatakan tidak valid

Arikunto (2010: 230) mengatakan untuk memperoleh reabilitas instrumen berupa tes digunakan rumus KR-20 sebagai berikut:

$$
r 11=\left(\frac{k}{k-1}\right)\left(\frac{v t-\sum p q}{v t}\right)
$$

\section{Keterangan :}

$$
\begin{aligned}
& r 11=\text { Reabilitas instrumen } \\
& P \quad=\text { Proporsi mahasiswa yang mendapat angka } 1 \text { pada suatu butir } \\
& P \quad=1-P \\
& K=\text { Banyaknya butir yang valid } \\
& V t=\text { Varians total }
\end{aligned}
$$

Kriteria reliabilitas instrumen butir soal sebagai berikut :

$$
r 11 \geq 0,70 \text { (reliabel) }
$$


$r 11<0,70($ tidak reliabel/ un-reliabel)

\section{HASIL DAN PEMBAHASAN}

Hasil yang diperoleh dari 7 item soal essay,diberikan kepada 10 mahasiswa Prodi Pendidikan Teknik Bangunan Universitas Palangka Raya, dalam pre-test ini diberikan untuk langkah awal yang dilakukan peneliti untuk mengukur kemampuan mahasiswa sebelum mengikuti mata kuliah Matematika Dasar.

Tabel. 2 Data Distribusi Frekuensi Pre-test (Tes Awal).

\begin{tabular}{ccc}
\hline NO & Kelas Interval & Frekuensi \\
\hline 1 & $27-31$ & 1 \\
\hline 2 & $32-36$ & 2 \\
\hline 3 & $37-41$ & 2 \\
\hline 4 & $42-46$ & 1 \\
\hline 5 & $47-51$ & 2 \\
\hline 6 & $52-56$ & 2 \\
\hline & & $\mathbf{N}=\mathbf{1 0}$
\end{tabular}

Dari Tabel 2 di atas didapat bahwa semua masih di bawah rata-rata karena masih belum diberikan perlakuan guided discovery learning dengan google classroom dipadukan tatap muka terbimbing.

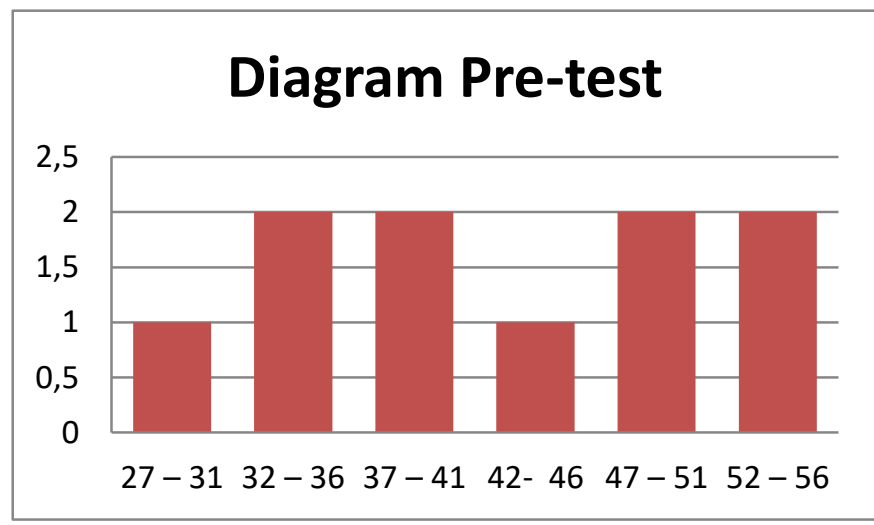

Gambar 2. Diagram batang Distribusi Frekuensi Skor Pre-test

Post-test yang diberikan merupakan hasil dari kemampuan peserta didik setelah dilakukanya perlakuan dengan menggunakan model pembelajaran guided discovery learning. Post-test diberikan untuk melihat pengaruh sesudah menggunakan model pembelajaran guided discovery learning yang dilihat dengan berdasarkan pre-test yang sebelumya dilakukan. Selain itu juga post-test merupakan evaluasi untuk melihat ketercapain hasil belajar setelah dilakukaan kegiatan pembelajaran.

Tabel. 3 Data hasil Post-test (tes Akhir) 


\begin{tabular}{ccc}
\hline NO & Kelas Interval & Frekuensi \\
\hline 1 & $60-65$ & 1 \\
\hline 2 & $66-71$ & 1 \\
\hline 3 & $72-77$ & 3 \\
\hline 4 & $78-83$ & 3 \\
\hline 5 & $84-89$ & 1 \\
\hline 6 & $90-95$ & 1 \\
\hline & & $\mathbf{N}=\mathbf{1 0}$ \\
\hline
\end{tabular}

Sumber: Data Hasil Perhitungan

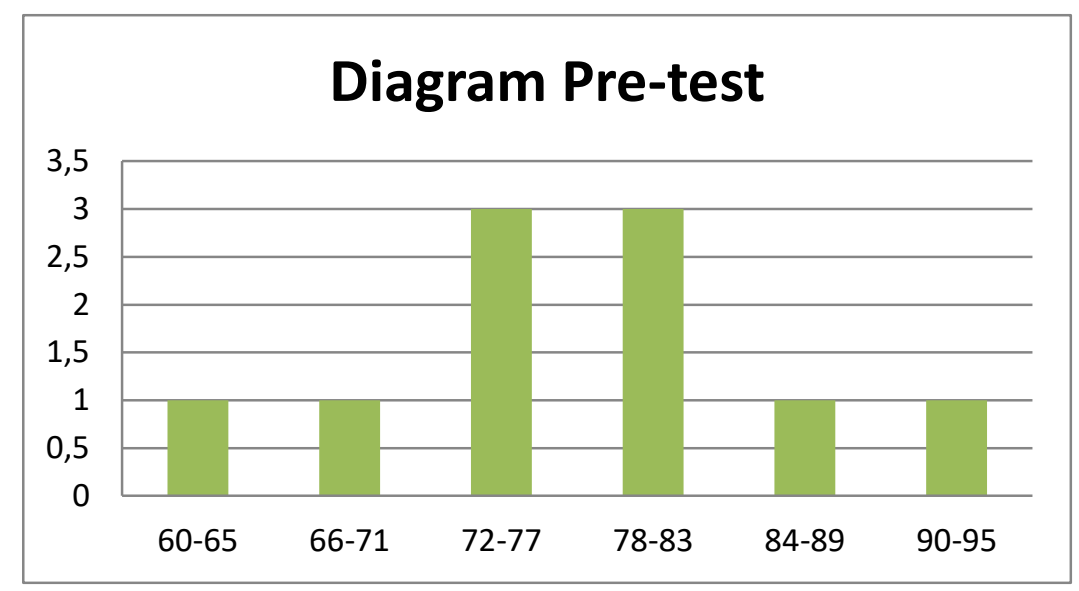

Gambar 3. Distribusi Frekuensi data Post-test

Berdasarkan perhitungan untuk uji normalitas pre-test belajar siswa diperoleh harga $\mathrm{X}^{2}$ hitung sebesar $\mathbf{8 , 4 3}$. Uji normalitas terhadap hasil belajar (posttest) siswa diperoleh harga $X^{2}$ tabel sebesar 8,65. Harga-harga tersebut selanjutya di di konfersikan dengan nilai harga $X^{2}$ hitung $<X^{2}$ tabel. Adapun harga di tentukan dengan derajat kebebesan $(\mathbf{d b})=\mathbf{5 - 1}=\mathbf{4}$ adalah 10,02, jadi hasil dari perhitungan data yang di peroleh berdistribusi normal.

Dari data-data yang telah dikumpulkan akan diolah untuk menjawab rumusan masalah yang telah disusun yaitu bagaimanakah pengaruh model pembelajaran tipe guided discovery learning terhadap hasil belajar siswa pada mata kuliah Matematika Teknik Prodi Pendidikan Teknik Bangunan FKIP Universitas Palangka Raya. Untuk menjawab rumusan masalah tersebut digunakan perhitungan $u j i-t$ untuk mengetahui perbandingan antara dua variabel atau model pembelajaran serta dapat mengetahui perbedaan atau tidaknya hasil perhitungan kedua model pembelajaran yang dikonsultasikan terhadap ttabel dan thitung.

Untuk mengetahui hasil perhitungan model one group pre-test post-test design maka peneliti menggunakan rumusan uji-t ( $t$-test) untuk pengukuran berulang, karena yang diteliti berpasangan maka data yang diperoleh tersebut di atas dianalisa dengan menggunakan tabel perbandingan pre-test dan post-test. 
Tabel 4. Data Perbandingan Nilai Pre-Test dan Post Test ( Sebelum dan Sesudah Menggunakan model pembelajaran guided discovery learning).

\begin{tabular}{ccccc}
\hline No subjek & Nilai pre-test & Nilai post-test & Selisih(D) & $\mathbf{D}^{2}$ \\
\hline 1 & 30 & 65 & 35 & 1225 \\
\hline 2 & 35 & 70 & 35 & 1225 \\
\hline 3 & 35 & 75 & 40 & 1600 \\
\hline 4 & 40 & 75 & 35 & 1225 \\
\hline 5 & 40 & 75 & 35 & 1225 \\
\hline 6 & 45 & 80 & 35 & 1225 \\
\hline 7 & 50 & 80 & 30 & 900 \\
\hline 8 & 50 & 80 & 30 & 900 \\
\hline 9 & 55 & 85 & 30 & 900 \\
\hline 10 & 55 & 90 & 35 & 1225 \\
\hline Jumlah & $\mathbf{4 3 5}$ & $\mathbf{7 7 5}$ & $\mathbf{3 4 0}$ & $\mathbf{1 1 6 5 0}$ \\
\hline Rata-rata & $\mathbf{4 3 , 5}$ & $\mathbf{7 7 , 5}$ & $\mathbf{3 4 , 0}$ & $\mathbf{1 1 6 5 , 0}$ \\
\hline
\end{tabular}

(sumber: Data Hasil pre-test dan post-test)

Dari data di atas bahwa nilai pre-test pada mata kuliah Matematika Teknik rata-rata sebesar 43,5 sedangkan post-test nya mempuyai rata-rata sebesar 77,5.

Dalam pengujian hipotesis ini digunakan analisi uji t-testuntuk mengetahui hasil dari analis apakah signifikan atau tidak. Maka dijelaskanlah Ha dan Ho sebagai berikut :

$\mathrm{Ha}$ : Terdapat pengaruh model pembelajaran guided discovery learning terhadap hasil belajar mahasiswa pada Mata Kuliah Matematika Teknik Prodi Pendidikan Teknik Bangunan FKIP UPR Tahun Akademik 2020/2021.

Ho : Tidak terdapat pengaruh model pembelajaran guided discovery learning terhadap hasil belajar mahasiswa pada Mata Kuliah Matematika Teknik Prodi Pendidikan Teknik Bangunan FKIP UPR Tahun Akademik 2020/2021.

Uji hipotesis yang dilakukan untuk membuktikan hipotesis di atas maka dari hasil analisis dapat dilihat pada Tabel 5 berikut :

Tabel 5. Data Hasil Analisis

\begin{tabular}{cccc}
\hline $\mathrm{D} f$ & T hitung & $\begin{array}{c}\text { T tabel dengan } \\
\text { kepercayaan } \mathbf{0 , 0 5}\end{array}$ & Hasil \\
\hline 10 & 2,06 & 2,02 & t hitung > t tabel \\
\hline
\end{tabular}

(Sumber: tabel daftar $t$ )

Berdasarkan hasil perhitungan di atas maka di peroleh nilai $\mathrm{t}$ sebesar $=22,1$ dimana df (degree of fredoom) dari data tersebut adalah( $n-1)$, sehingga untuk 
perhitungan ini d.b (derajat kebebebasan), $(10-1)$. Harga kritisnya pada tingkat kepercayaan $5 \%$ adalah 2,06. Maka dari thitung dan $t$ tabel dapat disimpulkan bahwa $t$ hitung $>t$ tabel yang berarti

“ Terdapat pengaruh model pembelajaran blended learning terhadap hasil belajar mahasiswa pada Mata Kuliah Matematika Teknik Prodi Pendidikan Teknik Bangunan FKIP UPR Tahun Akademik 2020/2021” dan hipotesis Ho ditolak.

Pengujian hipotesis dapat digambarkan dengan kurva sebagai berikut:

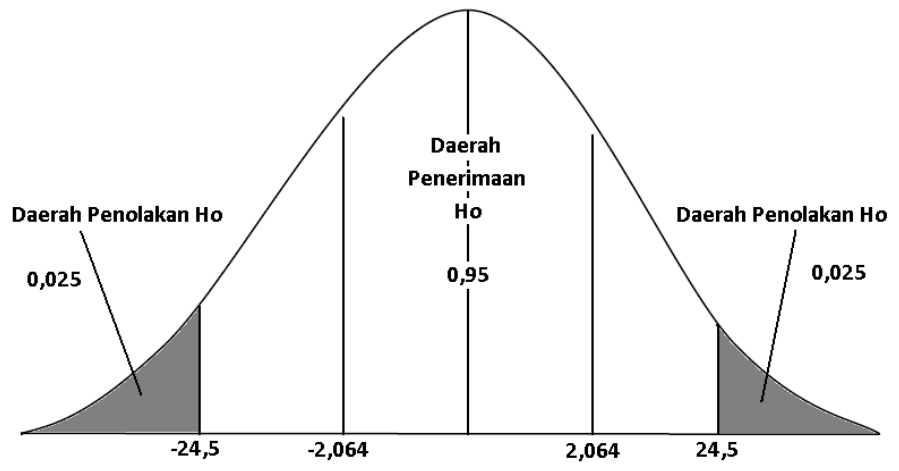

Gambar 4. Kurva Pengujian Hipotesis

Perhitungan pre-test nilai tertinggi adalah 55 dan nilai terendah 30, perhitungan untuk post-test tertinggi adalah 90 sedangakan nilai terendahnya 65 . Itu membuktikan bahwa hasil belajar meningkat Mata Kuliah Matematika Teknik Prodi Pendidikan Teknik Bangunan FKIP UPR Tahun Akademik 2020/2021 dengan model pembelajaran guided discovery learning.

\section{KESIMPULAN}

Sesuai dengan hasil penelitian dan analisis yang sudah diuraikan maka dapat ditarik kesimpulan sebagai berikut:

Terdapat pengaruh yang signifikan dibuktikan dengan analisi uji t-test dengan hasil $t_{\text {hitung }}>t_{\text {tabel }}$ dengan nilai thitung $=\mathbf{2 2 , 1}$ sedangkan untuk ttabel= 2,04 dengan kepercayaan $\mathbf{0 , 0 5 \%}$, maka dapat perbedaan yang signifikan pada pembelajaran yang menggunakan model pembelajaran guided discovery learning

\section{DAFTAR RUJUKAN}

Arikunto,Suharsimi. (2005). Prosedur Penelitian Suatu Pendekatan Praktik (Edisi

Revisi V).Jakarta : PT Asdi Mahasatya, Jakarta.

Asmawi Zainul, Noehi Nasoetion, MA (2007). Penilain Hasil Belajar .P2T Universitas Terbuka.

Budi Murtiayasa. (2015). Tantangan Pembelajaran Matematika Era Gobal.

Surakarta : Jurnal: Universitas Muhammadiyah Sukarta

Dimyati, Midjiono. (2006). Belajar dan Pembelajaran. Jakarta: Rineka Cipta 
Erman Suherman, dkk. (2013). Strategi Pembelajaran Matematika Komtemporer. Bandung: JICA

Gaol, C. E. L., \& Coenraad, R. (2015). The Influence Of Learning Model Cooperative Script Type On Student Learning Outcomes In The Material Of Identifying The Tile Floor And Wall Construction Engineering Grade XI Stone And Concrete (TKBB) SMKN 1 Palangka Raya Academic Year 2014/2015. PARENTAS: Jurnal Mahasiswa Pendidikan Teknologi dan Kejuruan, 1(1), 36-43.

Kosmawanti, C., \& Coenraad, R. (2017). Implementation Of Cooperative Learning Model Using Type Of Number Head Together (NHT) On Material Of Specification And Concrete Characteristic, Ceramic, And Roof-Tile For Building Construction In Class Of Concrete Engineering Concentration SMK Negeri 1. PARENTAS: Jurnal Mahasiswa Pendidikan Teknologi dan Kejuruan, 3(2), 78-89.

Novi Maulidar, yusrizal dan A. halim, Pengaruh Penerepan Model Pembelajaran Guided Discovery Terhadap Kemampuan Pemahaman Konsep dan Ketrampilan perpikir Kritis Siswa SMP, Jurnal Pendidikan Sains Indonesia (online), Vol.04, No.02, Diakses 2016, dari situs: https://media.neliti.com/media/publications/121489-ID-pengaruhpenerepan-model-pembelajarangu.pdf.

Rusniati, "Pendidikan Nasional dan Tantangan Globalisasi: Kajian Kritis Terhadap Pemikiran A.Malik Fajar". Jurnal Ilmiah DIDAKTIKA, Vol.16, No.1. Diakses pada Agustus 2015 dari situs: https://media.neliti.com/media/publications/136840-ID-pendidikannasional-dantantangan-global.pdf.

Slameto (2010). Belajar dan Faktor-Faktor yang Mempengaruhinya. Jakarta: Rineka Cipta

Sugiyono (2009). Metode Penelitian Pendidikan, pendekatan kuantitatif, kualitatif, dan R\&D. Bandung: Alfabeta CV.

Sugiyono (2014). Metod Penelelitian kuantitatif, kualitatif, dan R\&D. Bandung: Alfabeta CV.

Trianto. (2013). Mendesain model pembelajaran inovatif-progresif : Konsep, Landasan, dan Implementasinya pada Kurikulum Tingkat Satuan Pendidikan (KTSP). Jakarta: Kencana Prenada Media Group. 